\title{
Targeted Neonatal Echocardiography-Guided Therapy in Vein of Galen Aneurysmal Malformation: A Report of Two Cases with a Review of Physiology and Approach to Management
}

\author{
R. E. Giesinger, MD, FRCPC 1,2 Y. N. Elsayed, MD, $\mathrm{PhD}^{3,4}$ M. P. Castaldo, MD, FRCPC 1,2 \\ P. J. McNamara, MB, MSC ${ }^{1,2,5}$
}

${ }^{1}$ Division of Neonatology, The Hospital for Sick Children, Toronto, Canada
2 Departments of Paediatrics, University of Toronto, Toronto, Ontario,
Canada
${ }^{3}$ Division of Neonatology, Health Sciences Centre, Winnipeg,
Manitoba, Canada
4 Faculty of Health Sciences, University of Manitoba, Winnipeg,
Manitoba, Canada
${ }^{5}$ Department of Physiology, University of Toronto, Toronto, Ontario,
Canada

Address for correspondence Patrick J. McNamara, MB, MSC, Division of Neonatology, The Hospital for Sick Children, 555 University Avenue, Toronto, ON M5G $1 \times 8$, Canada (e-mail: patrick.mcnamara@sickkids.ca).

Am J Perinatol Rep 2019;9:e172-e176.

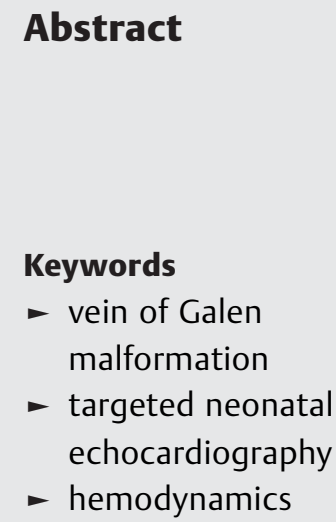

Abstract

Neonates with vein of Galen aneurysmal malformation (VGAM) present with a variety of systemic and pulmonary cardiovascular manifestations due to high-volume preductal left-to-right shunt. In utero maldevelopment of the pulmonary vascular bed due to overcirculation may lead to severe pulmonary hypertension (PH), ${ }^{1}$ presenting at birth as hypoxic respiratory failure. The postnatal cardiovascular course represents a pathophysiologic continuum from asymptomatic to the progressive development of hypotension, and impaired organ perfusion. Studies have shown that early neonatal cardiovas-

received

November 15, 2018 accepted after revision March 5, 2019
DOI https://doi.org/ $10.1055 / \mathrm{s}-0039-1688765$. ISSN 2157-6998. cular decompensation is a marker of poor outcome with a high mortality rate without treatment. ${ }^{2}$ Treatment using staged endovascular embolization requires admission to a specialized center; however, attaining cardiovascular stability prior to embolization may be challenging. ${ }^{3}$ These patients represent a unique population, rarely seen by most neonatologists. The clinical presentation and degree of hemodynamic compromise may be variable meriting standardization of the approach to assessment and therapeutic intervention. Targeted neonatal echocardiography (TnECHO) by trained neonatologists is used
Copyright $\odot 2019$ by Thieme Medical Publishers, Inc., 333 Seventh Avenue, New York, NY 10001, USA. Tel: +1(212) 584-4662.
License terms

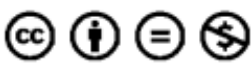


in many centers across the world to manage pulmonary and systemic hemodynamics. ${ }^{4-8}$ Most neonatologists with this advanced skill and fundamental knowledge of cardiovascular physiology will see a large volume of critically ill newborns with acute $\mathrm{PH}$, right ventricular dysfunction, and hemodynamic compromise where the range of physiologic derangement may be comparable with that of neonates with VGAM. In this report of two representative but complex cases, we describe the value of novel physiological insights gained from comprehensive TnECHO assessment and provide a systematic approach to preoperative stabilization.

\section{Case 1}

A male infant was born at 38 weeks by emergency cesarean section for poor biophysical profile at a rural hospital. Fetal assessment performed on the day of delivery revealed a large brain vascular malformation. Postnatal adaptation was good apart from mild respiratory depression that responded to routine resuscitation and birth weight was $3.9 \mathrm{~kg}$. The infant was transferred to the regional tertiary neonatal intensive care unit (NICU) on continuous positive airway pressure (CPAP). Magnetic resonance imaging (MRI) of the brain on postnatal day 1 confirmed a large vein of Galen aneurysmal malformation (VGAM). An anatomic echocardiogram demonstrated right-to-left shunt at both the ductal and foraminal levels and a dilated right ventricle (RV) with RV systolic dysfunction. A diagnosis of $\mathrm{PH}$ was made. The fraction of inspired oxygen $\left(\mathrm{FiO}_{2}\right)$ administered had increased from room air at transfer to 1.0 on CPAP $7 \mathrm{cmH}_{2} \mathrm{O}$; therefore, $20 \mathrm{ppm}$ of inhaled nitric oxide (iNO) was initiated noninvasively. Immediate reduction in $\mathrm{FiO}_{2}$ to 0.3 was observed. On postnatal day 2, he developed evidence of end-organ compromise and a TnECHO consultation was requested. Bidirectional ductal shunt, normal RV systolic performance, and high biventricular output with a ratio of right ventricular output (RVO) to left ventricular output (LVO) of 1.5 were identified ( - Table 1). An intravenous infusion of dobutamine was initiated and then escalated to a dose of $10 \mu \mathrm{g} / \mathrm{kg} / \mathrm{min}$. The patient subsequently developed oliguria and significant lactic acidosis on postnatal day 3. Repeat TnECHO demonstrated a closing ductus arteriosus (DA) with bidirectional flow, severe RV dysfunction, and reduced RVO with an RVO: LVO of 0.42 . Mechanical ventilation and prostaglandin $E_{1}$ were started and transfer to an embolization center was arranged. At the time of transfer, despite stable ventilation with $\mathrm{FiO}_{2} 0.28$ and iNO 20 ppm, and treatment with dobutamine and prostaglandin, lactic acidosis and severe oliguria recurred. TnECHO assessment demonstrated a large, predominantly left-to-right DA with normal RV systolic performance. iNO was discontinued and respiratory support modified to encourage right-to-left DA flow, which was temporally related to normalization of both the lactic acidosis and urine output. Follow-up TnECHO demonstrated a

Table 1 Clinical and echocardiography course of case 1

\begin{tabular}{|c|c|c|c|c|c|}
\hline Postnatal age (d) & 2 & 3 & 4 & 4 & 7 \\
\hline \multicolumn{6}{|l|}{ Clinical condition } \\
\hline $\begin{array}{l}\text { Preductal arterial } \\
\text { pressure }(\mathrm{mm} \mathrm{Hg})\end{array}$ & $55 / 34$ & $65 / 36$ & $68 / 22$ & $66 / 40$ & $52 / 44$ \\
\hline Urine output $(\mathrm{mL} / \mathrm{kg} / \mathrm{h})$ & 0 & 1.8 & 0 & 3.6 & 0.7 \\
\hline Lactate $(\mathrm{mmol} / \mathrm{L})$ & & 8.0 & 5.1 & 1.3 & 4.4 \\
\hline Preductal $\mathrm{SpO}_{2}(\%)$ & 95 & 93 & 92 & 92 & 92 \\
\hline $\mathrm{FiO}_{2}$ & 0.5 & 0.35 & 0.28 & 0.26 & 0.21 \\
\hline Ventilation $\left(\mathrm{cmH}_{2} \mathrm{O}\right)$ & CPAP 7 & VG $4.5 \mathrm{~mL} / \mathrm{kg}$, PEEP 7 & VG $4.5 \mathrm{~mL} / \mathrm{kg}$, PEEP 7 & $\begin{array}{l}\text { VG } 4.5 \mathrm{~mL} / \mathrm{kg} \text {, } \\
\text { PEEP } 7\end{array}$ & $\begin{array}{l}\text { VG } 4.5 \mathrm{~mL} / \mathrm{kg} \text {, } \\
\text { PEEP } 7\end{array}$ \\
\hline Adjunct therapy & iNO & iNO, dobutamine & iNO, dobutamine, PGE & Dobutamine, PGE & \\
\hline \multicolumn{6}{|l|}{ TnECHO findings } \\
\hline $\begin{array}{l}\text { Ductal shunt direction } \\
\text { and pattern }\end{array}$ & $\begin{array}{l}\text { Bidirectional } \\
\text { unrestrictive }\end{array}$ & Small restrictive & Mainly $L \rightarrow R$ unrestrictive & $\begin{array}{l}\mathrm{R} \rightarrow \mathrm{L} \text { large } \\
\text { unrestrictive }\end{array}$ & $\begin{array}{l}\mathrm{R} \rightarrow \mathrm{L} \text { small, } \\
\text { unrestrictive }\end{array}$ \\
\hline TAPSE $(\mathrm{mm})$ & 11.8 & 5.1 & 10.2 & 11.1 & 4.7 \\
\hline $\mathrm{RVO}(\mathrm{mL} / \mathrm{min} / \mathrm{kg})$ & 550 & 190 & 320 & 460 & 210 \\
\hline Ejection fraction (\%) & 54 & 62 & 63 & 56 & 62 \\
\hline $\mathrm{LVO}(\mathrm{mL} / \mathrm{min} / \mathrm{kg})$ & 365 & 454 & 360 & 330 & 340 \\
\hline RVO:LVO ratio & 1.5 & 0.42 & 0.89 & 1.4 & 0.62 \\
\hline \multicolumn{6}{|c|}{ Recommendations and response } \\
\hline Therapy & Dobutamine & Prostaglandin & Stop iNO & $\downarrow$ PGE and dobutamine & $\begin{array}{l}\text { Dobutamine } \\
\text { restarted }\end{array}$ \\
\hline Response & $\uparrow$ Urine output & $\downarrow$ Lactate to $3.0 \mathrm{mmol} / \mathrm{L}$ & $\begin{array}{l}\downarrow \text { Lactate to } 2.0 \mathrm{mmol} / \mathrm{L} \\
\uparrow \text { Urine output }\end{array}$ & $\begin{array}{l}\text { Gradual } \uparrow \text { Lactate } \\
\downarrow \text { Urine output }\end{array}$ & $\begin{array}{l}\downarrow \text { Lactate to } \\
1.6 \mathrm{mmol} / \mathrm{L} \\
\uparrow \text { Urine output }\end{array}$ \\
\hline
\end{tabular}

Abbreviations: CPAP, continuous positive airway pressure; $\mathrm{FiO}_{2}$, fraction of inspired oxygen; iNO, inhaled nitric oxide; LVO, left ventricular output; PEEP, positive end-expiratory pressure; $\mathrm{PGE}$, prostaglandin $\mathrm{E}$; $\mathrm{RVO}$, right ventricular output; $\mathrm{SpO}_{2}$, oxygen saturation; TAPSE, tricuspid annulus plane systolic excursion; TnECHO, targeted neonatal echocardiography; VG, volume guarantee. 
large right-to-left DA with normal RV performance and RVO: LVO of 1.4. Once stable, weaning cardiovascular support was attempted but due to recurrence of poor perfusion and severe RV dysfunction, he underwent successful VGAM embolization with symptomatic improvement.

\section{Case 2}

A female infant was born by vaginal delivery following an uncomplicated pregnancy at 37 weeks with a birth weight of $2.4 \mathrm{~kg}$. Shortly after delivery, she was noticed to be visibly cyanotic with right hand oxygen saturation $\left(\mathrm{SpO}_{2}\right)$ of $70 \%$. She required $3 \mathrm{~L}$ of flow via nasal canula in $\mathrm{FiO}_{2}$ of 1.0 to achieve a preductal $\mathrm{SpO}_{2}$ of $90 \%$. Pre- and postductal arterial pressures were 52/29 (37), right arm and right leg were 41/35 (37), respectively. She was transferred to the local tertiary NICU at 4 hours postnatal age where she was placed on $\mathrm{CPAP}$ in $\mathrm{FiO}_{2}$ of 0.5. An anatomic echocardiogram was done due to suspicion of congenital heart disease. A large DA with right-to-left shunt and a dilated right heart with normal biventricular systolic performance was thought to be in keeping with transitional circulation. On postnatal day 2 , a head ultrasound, done to evaluate decreased tone, was suggestive of VGAM. Despite initiation of furosemide, she remained oliguric and a capillary blood gas demonstrated evidence of metabolic acidosis ( $\mathrm{pH}$ of
7.14, $\mathrm{CO}_{2}$ of 48 , and $\mathrm{HCO}_{3}$ of 15 ). She was electively intubated for transport to an embolization center. Upon arrival to our center, she was noted to be critically unwell; specifically, she remained ventilated on moderate settings in $\mathrm{FiO}_{2}$ of 0.65 and had low preductal systolic arterial pressure, oliguria, and elevated lactate (-Table 2). TnECHO evaluation demonstrated a small, restrictive right-to-left DA with moderateto-severe RV dysfunction and RVO:LVO ratio of 1.5 (- Table 2). An intravenous infusion of dobutamine was initiated at a dose of $5 \mu \mathrm{g} / \mathrm{kg} / \mathrm{min}$ and increased to $10 \mu \mathrm{g} / \mathrm{kg} / \mathrm{min}$, but only with modest improvement after 4 hours; therefore, prostaglandin $\mathrm{E}_{1}$ was added. $\mathrm{FiO}_{2}$ subsequently declined to 0.45 with concomitant improvement in arterial pressure, urine output, and lactate. On postnatal day 3 , she was transferred to the radiology department for MRI of the brain. During the procedure, she acutely desaturated to preductal $\mathrm{SpO}_{2}$ of $75 \%$, despite $\mathrm{FiO}_{2}$ of 1.0 and iNO which had been started empirically a priori. Subsequent TnECHO demonstrated a large, exclusively right-to-left DA with normal RV systolic performance and high RVO with an RVO:LVO of 2.4 (-Table 2). Despite attaining clinical stability, the multidisciplinary team of a neonatologist, neurologist, neurosurgeon, and neurointerventionalist recommended withdrawal of intensive care based on severe white matter disease and poor neurological prognosis.

Table 2 Clinical and echocardiography course of case 2

\begin{tabular}{|c|c|c|c|c|}
\hline Postnatal age (d) & 2 & $2^{+4 h}$ & $2^{+4 h}$ & 3 \\
\hline \multicolumn{5}{|l|}{ Clinical condition } \\
\hline $\begin{array}{l}\text { Preductal arterial } \\
\text { pressure }(\mathrm{mm} \mathrm{Hg})\end{array}$ & $49 / 37$ & $53 / 36$ & $64 / 36$ & $60 / 43$ \\
\hline Urine output $(\mathrm{mL} / \mathrm{kg} / \mathrm{h})$ & 0.1 & 0.3 & 1.2 & 4.9 \\
\hline Lactate $(\mathrm{mmol} / \mathrm{L})$ & 5.5 & 5 & 2.5 & 1.3 \\
\hline Preductal $\mathrm{SpO}_{2}(\%)$ & 90 & 93 & 92 & 92 \\
\hline $\mathrm{FiO}_{2}$ & 0.65 & 0.65 & 0.45 & 0.47 \\
\hline Ventilation $\left(\mathrm{cmH}_{2} \mathrm{O}\right)$ & $\begin{array}{l}\text { VG } 5 \mathrm{~mL} / \mathrm{kg} \text {, } \\
\text { PEEP } 7\end{array}$ & VG 5 mL/kg, PEEP 7 & VG 5 mL/kg, PEEP 7 & VG 5 mL/kg, PEEP 7 \\
\hline Adjunct therapy & & Dobutamine $10 \mu \mathrm{g} / \mathrm{kg} / \mathrm{min}$ & Dobutamine, $\mathrm{PGE}_{1}$ & iNO, dobutamine, $\mathrm{PGE}_{1}$ \\
\hline \multicolumn{5}{|l|}{ TnECHO findings } \\
\hline $\begin{array}{l}\text { Ductal shunt direction } \\
\text { and pattern }\end{array}$ & $\begin{array}{l}\mathrm{R} \rightarrow \mathrm{L} \text { moderate, } \\
\text { restrictive }\end{array}$ & $\mathrm{R} \rightarrow \mathrm{L}$ moderate, restrictive & $\begin{array}{l}\mathrm{R} \rightarrow \mathrm{L} \text { large } \\
\text { unrestrictive }\end{array}$ & $\mathrm{R} \rightarrow \mathrm{L}$ large unrestrictive \\
\hline TAPSE (mm) & 6.4 & 7.2 & 8.8 & 11.1 \\
\hline $\mathrm{RVO}(\mathrm{mL} / \mathrm{min} / \mathrm{kg})$ & 330 & 350 & 400 & 560 \\
\hline Ejection fraction (\%) & 57 & 60 & 62 & 56 \\
\hline LVO (mL/min/kg) & 220 & 215 & 218 & 230 \\
\hline RVO:LVO ratio & 1.5 & 1.6 & 1.8 & 2.4 \\
\hline \multicolumn{5}{|c|}{ Recommendations and response } \\
\hline Therapy & Dobutamine & Prostaglandin & iNO if $\uparrow \mathrm{FiO}_{2}>0.6$ & \\
\hline Response & & $\begin{array}{l}\downarrow \text { Lactate to } 3.4 \mathrm{mmol} / \mathrm{L} \\
\uparrow \text { Urine output }\end{array}$ & & \\
\hline
\end{tabular}

Abbreviations: $\mathrm{FiO}_{2}$, fraction of inspired oxygen; iNO, inhaled nitric oxide; LVO, left ventricular output; PEEP, positive end-expiratory pressure; PGE prostaglandin $\mathrm{E}_{1}$; $\mathrm{RVO}$, right ventricular output; $\mathrm{SpO}_{2}$, oxygen saturation; TAPSE, tricuspid annulus plane systolic excursion; TnECHO, targeted neonatal echocardiography. 
Table 3 Suggested medical management based on pathophysiolical phenotype

\begin{tabular}{|c|c|c|c|}
\hline & Right ventricular dysfunction & High PVR $\therefore$ low PBF & Pseudocoarctation $\therefore$ low SBF \\
\hline Clinical & $\begin{array}{l}\mathrm{FiO}_{2}>0.6 \\
\downarrow \text { Urine output } \\
\downarrow \text { Systolic arterial pressure } \\
\uparrow \text { Lactate/metabolic acidosis }\end{array}$ & $\begin{array}{l}\mathrm{FiO}_{2}>0.6 \\
\downarrow \text { Urine output } \\
\downarrow \text { Systolic arterial pressure } \\
\uparrow \text { Lactate/metabolic acidosis }\end{array}$ & $\begin{array}{l}\mathrm{FiO}_{2}<0.6 \\
\downarrow \text { Urine output } \\
\downarrow \text { Diastolic arterial pressure } \\
\uparrow \text { Lactate/metabolic acidosis }\end{array}$ \\
\hline Echocardiography & $\begin{array}{l}\text { RVOLVO } \\
\downarrow \text { TAPSE; } \downarrow \text { FAC }\end{array}$ & $\begin{array}{l}\text { RVOLVO } \\
\text { Ductal shunt more } L \rightarrow R\end{array}$ & \\
\hline $\begin{array}{l}\text { Desired physiologic } \\
\text { effect }\end{array}$ & $\begin{array}{l}\text { Augment heart function } \\
\text { and reduce afterload }\end{array}$ & Lower PVR to promote PBF & Facilitate right-to-left ductal shunt \\
\hline $\begin{array}{l}\text { Therapeutic } \\
\text { approach }\end{array}$ & $\begin{array}{l}\text { 1. Dobutamine or low } \\
\text { dose epinephrine } \\
\text { 2. iNO and/or PGE }\end{array}$ & $\begin{array}{l}\text { 1. Optimize } \mathrm{CO}_{2}, \mathrm{FiO}_{2} \\
\text { 2. Sedation/muscle relaxation } \\
\text { 3. iNO to reduce PVR }\end{array}$ & $\begin{array}{l}\text { 1. Prostaglandin } \\
\text { 2. Permissive hypercapnia, } \\
\text { lower target } \mathrm{SpO}_{2} \\
\text { 3. Dobutamine }\end{array}$ \\
\hline
\end{tabular}

Abbreviations: $\mathrm{CO}_{2}$, carbon dioxide; $\mathrm{FiO}_{2}$, fraction of inspired oxygen; iNO, inhaled nitric oxide; $\mathrm{LVO}$, left ventricular output; PBF, pulmonary blood flow; PGE, prostaglandin E; PVR, pulmonary vascular resistance; RVO, right ventricular output; SBF, systemic blood flow; TAPSE, tricuspid annulus plane systolic excursion.

\section{Discussion}

The immediate postnatal period is a time of physiological metamorphosis when changing pulmonary and systemic vascular resistance (SVR) are essential adaptations. The clinical presentation of VGAM in newborns represents a spectrum with multiple pathophysiological changes which may contribute to poor tissue oxygen delivery.

The approach to treatment of these patients requires careful physiologic delineation. Possible contributors to instability include impaired RV performance, low pulmonary blood flow due to high pulmonary vascular resistance, and

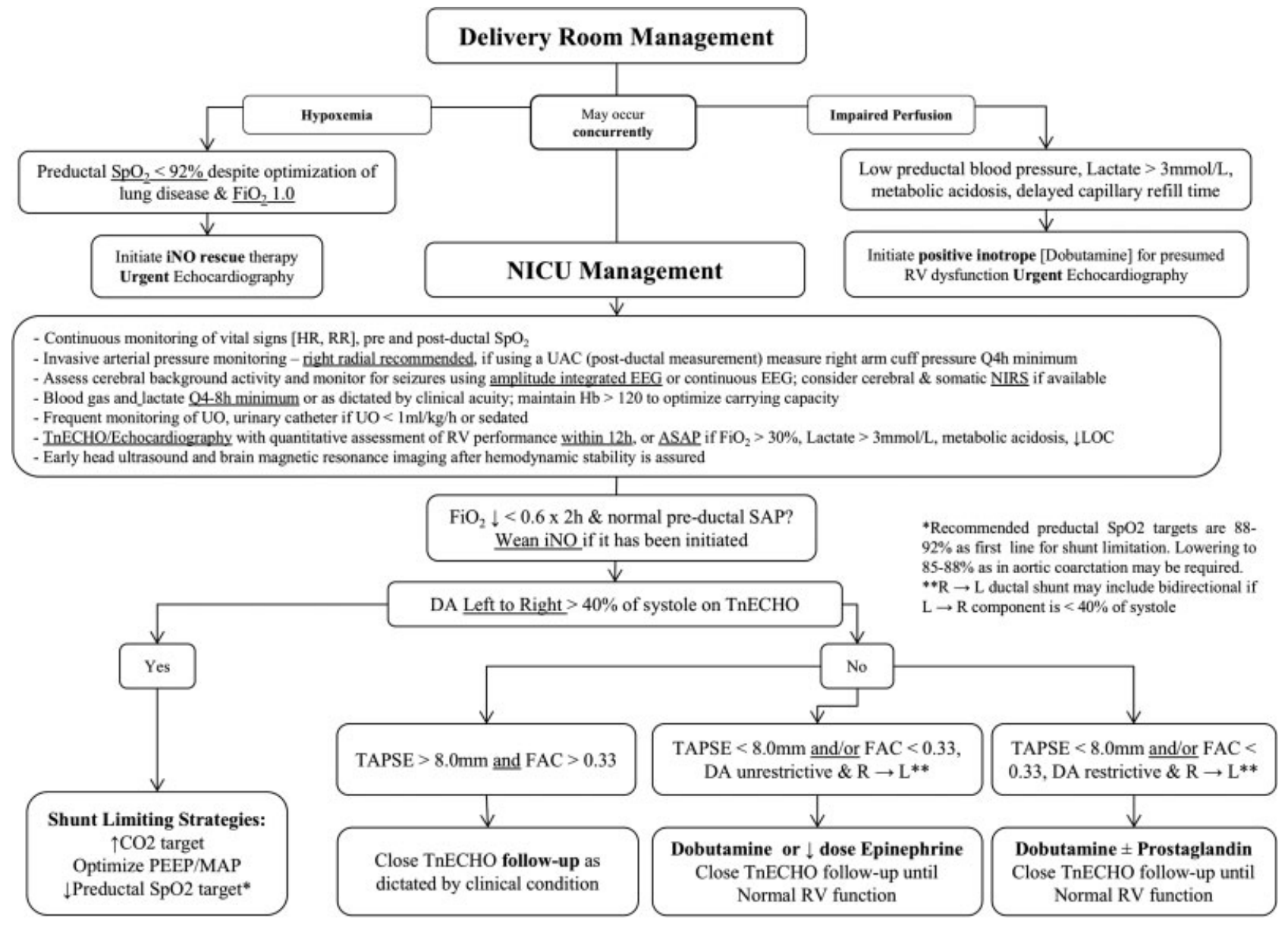

Fig. 1 Suggested management algorithm for the cardiovascular stabilization of neonates with vein of Galen aneurysmal malformation. $\mathrm{CO}_{2}$, carbon dioxide; DA, ductus arteriosus; EEG, electroencephalogram; $\mathrm{FAC}$, fractional area change; $\mathrm{FiO}_{2}$, fraction of inspired oxygen; $\mathrm{HR}$, heart rate; iNO, inhaled nitric oxide; L, left; LOC, level of consciousness; MAP, mean airway pressure; NICU, neonatal intensive care unit; NIRS, near-infrared spectroscopy; PEEP, positive end-expiratory pressure; $\mathrm{R}$, right; RR, respiratory rate; $\mathrm{RV}$, right ventricle; $\mathrm{SpO}_{2}$, oxygen saturation; TAPSE, tricuspid annulus plane systolic excursion; TnECHO, targeted neonatal echocardiography; UO, urinary output. 
pseudocoarctation physiology ( - Table 3 ). First, both high pulmonary blood flow with subsequent pulmonary vascular muscularization $^{9,10}$ with associated vascular hyperreactivity ${ }^{11}$ contribute to high pulmonary pressure. Second, chronic volume loading leads to RV dilation and therefore increased susceptibility to afterload mediated dysfunction ${ }^{12}$ and elevated energy demand. ${ }^{13}$ Finally, intracranial steal may contribute to heart dysfunction via low coronary root pressure and is associated with retrograde descending aortic flow which may cause pseudocoarctation physiology. Balancing the VGAM circulation requires pulmonary pressure to be sufficiently low to avoid RV decompensation and impaired cardiac output but not so low as to exacerbate systemic steal either via the VGAM or via left-to-right ductal shunt. Changing pulmonary pressure may precipitate dramatic changes in cardiovascular physiology which are difficult to piece together clinically. The use of iNO to improve oxygenation, therefore, requires careful consideration of timing and frequent reassessment to avoid precipitating pseudocoarctation as in our first case. In contrast, the combination of highly reactive pulmonary vasculature and a vulnerable RV may precipitate dramatic pulmonary hypertensive crisis in which iNO may be invaluable as in our second case. Documentation of normal RV systolic performance prior to any noxious stimulus is recommended.

We have developed an algorithm which recognizes the variance in phenotypic presentation and incorporates an approach to therapeutic intervention based on enhanced physiologic precision ( - Fig. 1). Dobutamine has favorable properties as a relatively pure inotrope. ${ }^{14}$ The avoidance of potent systemic vasoconstrictors (e.g., dopamine, epinephrine, norepinephrine, vasopressin) is recommended, unless there is an additional illness with low SVR such as sepsis. ${ }^{15}$ Milrinone, a nonselective vasodilator, may cause dangerously low diastolic arterial pressure and compromise coronary and organ perfusion pressure. It may be considered cautiously, however, in the setting of increased LV exposed afterload following embolization to support myocardial performance. Prostaglandin has a dual role including RV afterload reduction and postductal delivery of systemic blood flow which may be relatively protected from the impact of intracranial steal. The ability to provide longitudinal assessment makes TnECHO an important tool in the acute management of these infants and may also provide insights into disease prognosis. It has been suggested that high combined cardiac output is associated with mortality in fetuses with VGAM, ${ }^{16}$ and therefore, postnatal cardiac output may provide useful insight. Interestingly, both a higher ratio of RVO:LVO to achieve stable systemic blood flow and severe white matter injury were identified in the second case indicating a greater shunt magnitude. The complexity and delicate balance of disease pathophysiology illustrated in these cases highlight the importance of management of this rare disorder in centers with both the neurointerventional and neonatal hemodynamic experience to optimize their care.
Conflict of Interest

None.

\section{References}

1 Lakshminrusimha S, Wiseman D, Black SM, et al. The role of nitric oxide synthase-derived reactive oxygen species in the altered relaxation of pulmonary arteries from lambs with increased pulmonary blood flow. Am J Physiol Heart Circ Physiol 2007; 293(03):H1491-H1497

2 McSweeney N, Brew S, Bhate S, Cox T, Roebuck DJ, Ganesan V. Management and outcome of vein of Galen malformation. Arch Dis Child 2010;95(11):903-909

3 Frawley GP, Dargaville PA, Mitchell PJ, Tress BM, Loughnan P. Clinical course and medical management of neonates with severe cardiac failure related to vein of Galen malformation. Arch Dis Child Fetal Neonatal Ed 2002;87(02):F144-F149

4 Finan E, Sehgal A, Khuffash AE, McNamara PJ. Targeted neonatal echocardiography services: need for standardized training and quality assurance. J Ultrasound Med 2014;33(10):1833-1841

5 Amer R, Kalash R, Seshia MM, Elsayed YN. The impact of integrated evaluation of hemodynamics on management of preterm infants with late-onset compromised systemic circulation. Am J Perinatol 2017;34(10):1011-1019

6 Harabor A, Soraisham AS. Utility of targeted neonatal echocardiography in the management of neonatal illness. J Ultrasound Med 2015;34(07):1259-1263

7 Evans N. Echocardiography on neonatal intensive care units in Australia and New Zealand. J Paediatr Child Health 2000;36(02): 169-171

8 Papadhima I, Louis D, Purna J, et al. Targeted neonatal echocardiography (TNE) consult service in a large tertiary perinatal center in Canada. J Perinatol 2018;38(08):1039-1045

9 Dahdah NS, Alesseh H, Dahms B, Saker F. Severe pulmonary hypertensive vascular disease in two newborns with aneurysmal vein of Galen. Pediatr Cardiol 2001;22(06):538-541

10 Reddy VM, Meyrick B, Wong J, et al. In utero placement of aortopulmonary shunts. A model of postnatal pulmonary hypertension with increased pulmonary blood flow in lambs. Circulation 1995;92(03):606-613

11 Reddy VM, Wong J, Liddicoat JR, Johengen M, Chang R, Fineman JR. Altered endothelium-dependent responses in lambs with pulmonary hypertension and increased pulmonary blood flow. Am J Physiol 1996;271(2 Pt 2):H562-H570

12 Reller MD, Morton MJ, Reid DL, Thornburg KL. Fetal lamb ventricles respond differently to filling and arterial pressures and to in utero ventilation. Pediatr Res 1987;22(06):621-626

13 Altin SE, Schulze PC. Metabolism of the right ventricle and the response to hypertrophy and failure. Prog Cardiovasc Dis 2012;55 (02):229-233

14 Ruffolo RR Jr. The pharmacology of dobutamine. Am J Med Sci 1987;294(04):244-248

15 Barrington KJ, Finer NN, Chan WK. A blind, randomized comparison of the circulatory effects of dopamine and epinephrine infusions in the newborn piglet during normoxia and hypoxia. Crit Care Med 1995;23(04):740-748

16 Godfrey ME, Tworetzky W, Morash D, Friedman KG. Cardiac findings in the fetus with cerebral arteriovenous malformation are associated with adverse outcome. Fetal Diagn Ther 2017;41 (02):108-114 